\title{
Prediction of Location of the Parotid Tumors that Cross Over Anatomical Criteria for Facial Nerve on Computed Tomography
}

\author{
Gyu Ho Jang ${ }^{1}$, Deok Su Kim ${ }^{1}$, Young Do Jung, ${ }^{1}$ Youn Tae Seo ${ }^{1}$, Bo Mun Kim¹, \\ Bu Kwan Kil ${ }^{1}$, Dong Won Lee ${ }^{1}$, Ho Kyun Kim ${ }^{2}$, and Jeong Kyu Kim ${ }^{1}$ \\ ${ }^{1}$ Departments of Otolaryngology-Head and Neck Surgery, ${ }^{2}$ Radiology, Catholic University of Daegu School of Medicine, \\ Daegu, Korea
}

\section{전산화단층촬영에서 안면신경 해부학적 지표와 교차하는 이하선 종양의 위치예측}

장규호 ${ }^{1} \cdot$ 김덕수 $^{1} \cdot$ 정영도 $^{1} \cdot$ 서윤태 ${ }^{1} \cdot$ 김보문 $^{1} \cdot$ 길부관 $^{1} \cdot$ 이동원 $^{1} \cdot$ 김호균 $^{2} \cdot$ 김정규 $^{1}$

대구가톨릭대학교 의과대학 이비인후과학교실, ${ }^{1}$ 영상의학교실 ${ }^{2}$

Received August 9, 2018

Revised September 27, 2018

Accepted October 16, 2018

Address for correspondence

Jeong Kyu Kim, MD, PhD

Departments of Otolaryngology-

Head and Neck Surgery,

Catholic University of Daegu

School of Medicine,

33 Duryugongwon-ro 17-gil,

Nam-gu, Daegu 42472, Korea

Tel $+82-53-650-4071$

Fax $+82-53-650-4533$

E-mail doctorjkkim@cu.ac.kr
Background and Objectives To find more accurate way to determine the location of parotid tumors that cross anatomical criteria for the facial nerve (FN).

Subjects and Method Two hundred patients were included in the study and retrospectively studied. Five anatomical criteria were used to predict the location of parotid tumors on computed tomography (CT). Deep portion of tumors was measured and then, cut-off value was obtained after receiver operator curve analysis. The location of tumor was predicted by using the cut-off value and by the conventional way, in which the side where most of the tumor is located is determined as the tumor site.

Results The parotid tumors were located in superficial lobes in 148 cases, and in deep lobes in 52 cases by operative record. The tumors that cross the anatomical criteria were defined as 'crossing tumor.' The cut-off values for prediction of 'crossing tumor' location on CT were 6.7 $\mathrm{mm}$ for anatomical line, $6.4 \mathrm{~mm}$ for FN line, $11.2 \mathrm{~mm}$ for retromandibular vein, $4.9 \mathrm{~mm}$ for Utrecht line and $3.8 \mathrm{~mm}$ for Conn's arc. The accuracy of 5 anatomical criteria for 'crossing tumor' was between $55.9 \%$ and $81.6 \%$ when the cut-off value was used, whereas the accuracy was between $25.7 \%$ and $68.9 \%$ when conventional way was used.

Conclusion In cases of 'crossing tumor,' the cut-off value obtained by measurement of deep portion of tumor can be applied to improve the diagnostic performance for the prediction of tumor location.

Korean J Otorhinolaryngol-Head Neck Surg 2019;62(3):176-81
서 론

이하선 종양 수술 시 종양과 안면신경과의 관계는 매우 중 요하다. 종양이 이하선 천엽에 위치한 경우 이하선 천엽절제

This is an Open Access article distributed under the terms of the Creative Commons Attribution Non-Commercial License (https://creativecommons.org/licenses/by-nc/4.0) which permits unrestricted non-commercial use, distribution, and reproduction in any medium, provided the original work is properly cited.
술로 치료 가능하나, 이하선 심엽에 위치한 경우 이하선 전절 제술이 필요할 수도 있다. 이하선 심엽에 위치한 종양을 치료 하기 위해 이하선 전절제술을 시행할 경우 안면신경과 관련 된 합병증이 발생할 가능성이 높기 때문에 수술 전에 환자에 게 미리 정보를 제공해야 한다. ${ }^{1)}$

하지만 영상의학적 기술의 발전에도 불구하고, 안면신경은 전산화단층촬영(computed tomography, CT)이나 자기공명 
영상(magnetic resonance imaging, MRI)에서 관찰되지 않 는다. 이를 극복하기 위해 영상의학적 이미지에서 이하선 종 양의 위치를 예측하기 위한 여러 가지 해부학적 지표가 제시 되었다. ${ }^{2)}$

안면신경을 예측하는 해부학적 지표를 비교한 기존 연구들 3 ,4) 은 종양이 해부학적 지표에 걸쳐있는 경우 종양의 $50 \%$ 이상 이 해부학적 지표 보다 안쪽에 위치한 것을 심엽종양으로 분 류하여 연구를 진행하였다. 본 연구는 종양이 해부학적 지표 에 걸쳐있을 경우 심엽종양을 판단하기 위한 참고 값을 구하 여 예측 정확도를 향상시키기 위해 시행되었다.

\section{대상 및 방법}

\section{대상자의 선정기준}

2007년 1월부터 2016년 12월까지 이하선절제술을 시행한 230명의 환자에 대해 후향적으로 분석 하였다. 기록의 소실로 실제 종양의 위치가 파악되지 않는 경우, 수술기록에서 안면 신경 경부 분지의 하방에 위치한 이하선 미부 종양은 제외하 였다. 연구는 본 대학병원의 임상윤리위원회 심의를 승인 받았 다(IRB No. CR-17-052).

\section{안면신경의 해부학적 지표}

본 연구에서는 안면신경의 위치를 판단하기 위해 Anatomical line(A line), Facial nerve line(FN line), 하악후정맥 (Retromandibular vein, RV), Utrecht line(U line), Conn's $\operatorname{Arc}(\mathrm{CA})$ 의 5 가지 해부학적 지표를 사용하였다. A line은 안면

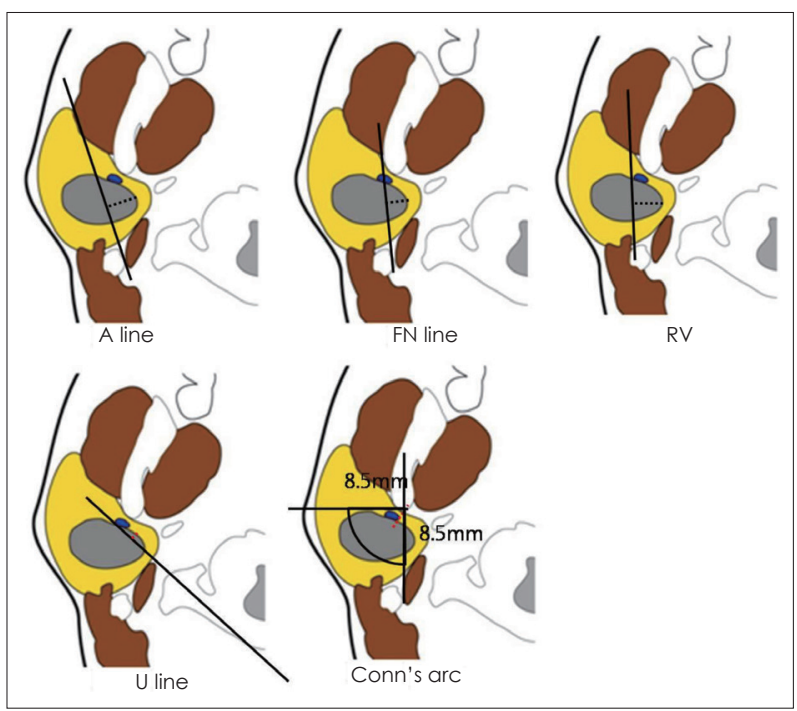

Fig. 1. Measurement of deep portion of tumors. Solid line: anatomic criteria, Dotted line: vertical lines to anatomic criteria to measure deep portion of tumors. A line: Anatomical line, FN line: Facial nerve line, RV: Retromandibular vein, $U$ line: Utrecht line, CA: Conn's arc.
신경 다발과 교근(masseter muscle)을 연결한 선이다. ${ }^{4)}$ 안면신 경 다발의 위치는 높은 위치의 단면인 경우 경상돌기(styloid process)와 유돌기(mastoid process)의 중간지점으로 추정하 였고, 낮은 위치의 단면인 경우 흥쇄유돌근(sternocleidomastoid muscle)과 후이복근(posterior belly of digastric muscle)의 중간지점으로 추정하였다. FN line은 후이복근의 측면과 동측턱뼈가지의 측면을 연결한 선을 의미한다. ${ }^{3)} \mathrm{RV}$ 의 측면 자체를 안면신경을 예측하는 해부학적 지표로 이용 하기도 한다. ${ }^{5)} \mathrm{U}$ line은 종양이 위치한 동측에서 관찰되는 척 추 뼈의 가장 뒤 부분과 RV를 연결한 선이다.) $\mathrm{U}$ line을 사용 할 경우 종양의 크기가 가장 크게 관찰되는 축영상(axial view) 이미지에서 척추 뼈의 가장 뒷부분을 해부학적 지표로 이용하 였다. CA는 턱뼈가지(mandibular ramus)의 뒤쪽 지점에서 $8.5 \mathrm{~mm}$ 거리에 위치한 호이다(Fig. 1).

\section{해부학적 지표를 적용한 전산화단층촬영 이미지의 이하 선 종양 위치 분석}

전산화단층촬영(computed tomography, CT)은 2대의 장 비(SOMATOM Definition Flash, Siemens Healthineers, Erlangen, Germany, and Discovery CT750 HD FREEdom Edition, GE Healthcare, Chicago, USA)가 사용되었으며 조 영제를 사용하여 $2 \mathrm{~mm}$ 두께로 촬영하였다. 이비인후과 전문 의 1 명과 영상의학과 전문의 1 명이 함께 영상을 판독했고, 위 에서 서술한 5 가지 종양의 위치예측 기준을 적용하여 위치를 평가했다.

전산화단층촬영 축영상 이미지 중 종양이 가장 크게 나타 나는 이미지를 선택하여 종양의 크기를 측정하고, 해당 이미 지에서 해부학적 지표를 적용하였다. 전산화단층촬영 축영상 이미지를 분석할 때 종양 전체가 해부학적 지표의 안쪽에 위 치한 경우 심엽에 위치한 것으로, 종양 전체가 해부학적 지표 의 바깥쪽에 위치한 경우 천엽에 위치한 것으로 예측하였다. 종양의 일부가 해부학적 지표에 걸쳐있는 경우 '교차종양'으 로 정의하였다.

'교차종양'에서 종양의 위치를 예측하기 위하여 해부학적 지표의 안쪽에 위치한 부분의 길이를 '침범깊이'로 정의하였 다. '침범깊이'는 A line, FN line, U line의 경우 기준에서 직 각으로 종양까지의 최대 길이를 측정하였고, 하악후정맥은 외측 끝에서 종양까지의 거리를 측정하였다. $\mathrm{CA}$ 의 경우 '침 범깊이를 적용할 수 없어 턱빼가지의 최후방 지점에서 종양 까지의 거리를 측정하여 '침범깊이'로 사용하였다(Fig. 1).

다음의 2 가지 방법으로 종양의 위치를 판단하였다. 첫 번 째로, '침범깊이'에 대한 receiver operating characteristic (ROC) 커브 분석을 통하여 절단값을 구하였다. A line, FN 
line, RV, U line에서는 '침범깊이'가 절단값보다 큰 경우 심 엽종양으로 판단 하였다. $\mathrm{CA}$ 의 경우는 '침범깊이'가 절단값 보다 작은 경우를 심엽종양으로 판단하였다. 두 번째로, 기존 의 방법대로 종양의 절반이상이 해부학적 지표 안쪽에 위치 한 경우를 심엽에 위치한 것으로 판단하였다.

해부학적 지표의 기준이 되는 구조물이 종양이 위치한 CT 사진에서 관찰되지 않는 경우를 '적용불가'로 정의 하였다. CA 의 경우 종양이 턱뼈가지 앞에 위치한 경우가 ‘적용불가'에 포 함되었다.

종양의 실제 위치는 수술 직후 작성된 수술 기록지를 통해 확인하였다. 종양의 전체가 안면신경줄기보다 바깥에 위치할 경우 ‘천엽종양', 종양의 전체가 안면신경줄기보다 안쪽에 위 치한 경우 ‘완전심엽종양', 종양의 일부분이 안면신경줄기보다 안쪽에 위치한 경우 '부분심엽종양', 안면신경의 경부분지보 다 하방에 종양이 위치하는 경우 '미부종양'으로 분류하였다.

\section{통계 분석}

통계 분석은 MedCalc Version 14.8.1(MedCalc Software Bvba, Ostend, Belgium)을 이용하였다. 각각의 해부학적 지 표에 대한 심엽종양 진단의 민감도, 특이도, 양성예측도, 음 성예측도, 정확도를 구하였다. 절단값을 구하기 위해 $\mathrm{ROC}$ 커 브분석을 시행하였다.

\section{결 과}

230 명의 환자 중 수술기록 확인이 불가능한 11 명의 환자와 미부종양 19 명을 제외한 200명이 연구에 포함되었다. 수술기 록지를 통해 확인된 실제 종양의 위치에 따른 환자 수는 천 엽종양 148 명, 완전심엽종양 40 명, 부분심엽종양은 12 명이었 다. 종양의 평균 크기는 $30 \mathrm{~mm}$ 였다.

전산화단층촬영에서 5 가지 해부학적 지표에 따라 이하선 종양의 위치를 판단한 결과는 Table 1과 같다. A line의 경우 91예, FN line은 38예, RV의 경우 74예, U line은 111예, CA 는 93예에서 '교차종양'으로 판정되었다.

'교차종양'에서 ‘침범깊이' 값에 대한 ROC 커브 분석 후
구한 절단값은 A line의 경우 $6.7 \mathrm{~mm}, \mathrm{FN}$ line은 $6.4 \mathrm{~mm}$, $\mathrm{RV}$ 는 $11.2 \mathrm{~mm}$, U line은 $4.9 \mathrm{~mm}, \mathrm{CA}$ 는 $3.8 \mathrm{~mm}$ 로 나타났 다(Fig. 2).

'교차종양'에서 절단값을 이용하여 종양의 위치를 예측하 였을 경우의 정확도, 민감도, 특이도, 양성예측도, 음성예측도 는 Table 2 와 같다. 5 가지 기준 중 FN line의 정확도(81.6\%), 민감도(93.8\%), 양성예측도(71.4\%)가 가장 높게 나타났고, $\mathrm{RV}$ 의 특이도(80.0\%)가 가장 높게 나타났다.

기존의 방법처럼 종양의 절반 이상이 해부학적 지표 안쪽 에 위치할 경우를 '심엽종양'으로 분류했을 때의 정확도, 민 감도, 특이도, 양성예측도, 음성예측도는 Table 3 과 같다. CA 의 경우 정의에 따라 걸쳐있는 종양은 모두 심엽종양으로 평 가하게 되므로 민감도, 특이도, 양성예측도, 음성예측도는 구 할 수 없었다.

절단값을 사용할 경우 U line을 제외한 4가지 해부학적 지표 에서 기존의 방법을 사용할 때 보다 정확도의 향상이 있었다. $\mathrm{CA}$ 의 경우 절단값을 이용하여 위치를 예측할 경우 $49.3 \%$ 의 정확도 향상이 있었다(Table 2 and 3).

\section{고 찰}

전산화단층촬영에서 해부학적 기준을 이용하여 이하선 종 양의 위치를 판단할 때 종양의 위치에 따라 기준이 되는 해부 학적 지표가 보이지 않는 경우가 있다. A line은 안면신경 다 발에서 교근에 그은 선을 이용하여 이하선 종양의 위치를 예 측한다. 다른 기준의 경우 종양의 위치에 따라 해부학적 기준 이 보이지 않는 경우가 많은데, A line의 경우 상대적으로 아 래쪽에 위치한 종양에 적용할 때도 교근이 잘 보여 적용 가 능한 케이스가 많았다. 하지만 종양이 커질수록 안면신경을 안쪽으로 밀고 종양은 바깥쪽으로 커지게 되므로 정확도가 떨어진다는 단점이 있다. ${ }^{8)} \mathrm{FN}$ line과 $\mathrm{CA}$ 의 경우 턱뼈가지를 해부학적 지표로 이용하는데 종양이 아래쪽에 위치한 경우 턱뼈가지가 보이지 않아(Fig. 3), 다른 기준에 비해 적용이 불 가능한 경우가 많았다(Table 1). 하악후정맥을 지표로 사용하 는 RV와 U line의 경우 하악후정맥을 관찰할 수 없어 적용이

Table 1. Prediction of parotid tumors using 5 anatomic criteria

\begin{tabular}{lcccc}
\hline \multicolumn{1}{c}{ Anatomic criteria } & Complete superficial & Crossing & Complete deep & Inapplicable \\
\hline A line & 96 & 91 & 3 & 10 \\
FN line & 114 & 38 & 0 & 48 \\
RV & 114 & 74 & 7 & 5 \\
U line & 64 & 111 & 12 & 13 \\
CA & 51 & 93 & 0 & 56 \\
\hline
\end{tabular}

A line: Anatomical line, FN line: Facial nerve line, RV: Retromandibular vein, U line: Utrecht line, CA: Conn's arc 
불가능한 경우가 있었다(Fig. 4). U line은 척추 뼈의 가장 뒷 부분을 기준으로 사용하는데 종양의 위치에 따라 척추 뼈의 가시돌기가 보이는 경우와 가시돌기가 보이지 않는 경우 해부
학적 지표의 변화가 컸다(Fig. 5).

종양이 해부학적 지표에 걸쳐있는 경우 해부학적 지표에서 부터 종양이 안쪽으로 들어간 거리가 멀수록 심엽에 위치할
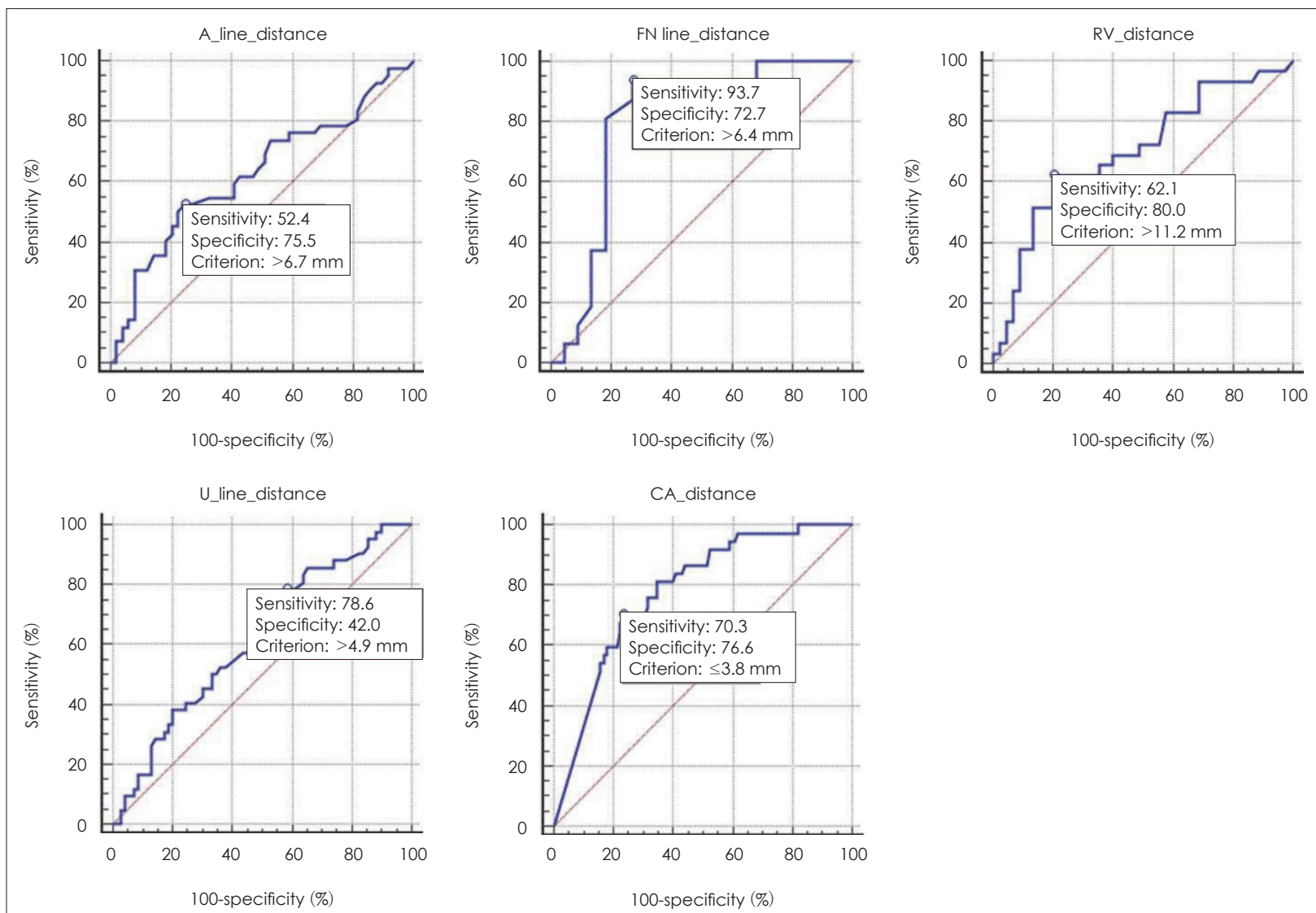

Fig. 2. Receiver operating characteristic analysis for 'crossing tumor.' A line: Anatomical line, FN line: Facial nerve line, RV: Retromandibular vein, U line: Utrecht line, CA: Conn's arc.

Table 2. Diagnostic performance of new method using cut-off value in parotid tumors that cross anatomic criteria

\begin{tabular}{lcccccc}
\hline \multicolumn{1}{c}{ Anatomic criteria } & Crossing & Accuracy (\%) & Sensitivity (\%) & Specificity (\%) & PPV (\%) & NPV (\%) \\
\hline A line & 91 & 64.8 & 52.4 & 75.5 & 64.7 & 64.9 \\
FN line & 38 & 81.6 & 93.8 & 72.7 & 71.4 & 94.1 \\
RV & 74 & 73.0 & 62.0 & 80.0 & 66.7 & 76.6 \\
U line & 111 & 55.9 & 78.6 & 42.0 & 45.2 & 76.3 \\
CA & 93 & 75.0 & 70.3 & 76.6 & 51.0 & 81.2 \\
\hline
\end{tabular}

A line: Anatomical line, FN line: Facial nerve line, RV: Retromandibular vein, U line: Utrecht line, CA: Conn's arc, No.: Number of crossing tumors, PPV: Positive predictive value, NPV: Negative predictive value

Table 3. Diagnostic performance of traditional method in parotid tumors that cross anatomic criteria

\begin{tabular}{lcccccc}
\hline \multicolumn{1}{c}{ Anatomic criteria } & Crossing & Accuracy (\%) & Sensitivity (\%) & Specificity (\%) & PPV (\%) & NPV (\%) \\
\hline A line & 91 & 57.1 & 11.9 & 95.9 & 71.4 & 55.9 \\
FN line & 38 & 57.8 & 6.3 & 95.5 & 50.0 & 58.3 \\
RV & 74 & 68.9 & 37.9 & 88.9 & 68.7 & 68.9 \\
U line & 111 & 55.9 & 21.4 & 76.8 & 36.0 & 61.6 \\
CA & 93 & 25.7 & - & - & - & -
\end{tabular}

A line: Anatomical line, FN line: Facial nerve line, RV: Retromandibular vein, U line: Utrecht line, CA: Conn's arc, No.: Number of crossing tumors, PPV: Positive predictive value, NPV: Negative predictive value 
가능성이 높다. 그래서 해부학적 지표에 걸쳐있는 종양들에 대한 $\mathrm{ROC}$ 커브 분석을 시행하여 절단값을 구하였다(Fig. 2). $\mathrm{CA}$ 에서 사용하는 '턱뼈가지의 뒤쪽 지점에서 $8.5 \mathrm{~mm}$ 거리에 위치한 호'는 5구의 카데바 연구를 통해 발표된 기준이다. ${ }^{7)}$ 기 존연구의 연구대상 수가 적다고 생각되어, 절단값을 이용한 예측 정확도를 높이기 위해 $\mathrm{CA}$ 의 경우 예외적으로 '적용불 가'에 해당하는 경우를 제외한 모든 경우에 대하여 ROC 커
브 분석을 시행하였다.

이하선 종양을 수술 할 때 심엽 종양의 경우 신경과 종양을 박리할 때 더욱 주의가 필요하므로 수술의 난이도가 높아진 다. 그러므로 술전 심엽종양에 대한 예측이 매우 중요하며 이를 반영하는 민감도와 양성예측도가 다른 예측 지표 보다 중요하다. $\mathrm{FN}$ line의 절단값 $6.4 \mathrm{~mm}$ 를 적용하여 해부학적 지표에 걸쳐있는 종양을 분석할 경우 민감도(93.8\%)와 양성
Fig. 3. Invisible mandibular ramus When the mandibular ramus is used as an anatomical landmark, the mandibular ramus is not seen when the tumor is located at the lower side. Mandibular ramus is visible $(A)$. Mandibular ramus is invisible (B). Arrowhead: mandible ramus, arrows: mass.

Fig. 4. Invisible RV. RV is visible (A) $\mathrm{RV}$ is invisible (B). Arrowhead: retromandibular vein, arrows: mass $\mathrm{RV}$ : retromandibular vein.

Fig. 5. Change of posterior portion of vertebra. Depending on the location of the tumor, the posterior part of the vertebra, which is the reference point, is different. Spinous process of vertebra is visible (A). Spinous process of vertebra is invisible (B). Arrowhead: vertebra spinous process, arrows: mass.
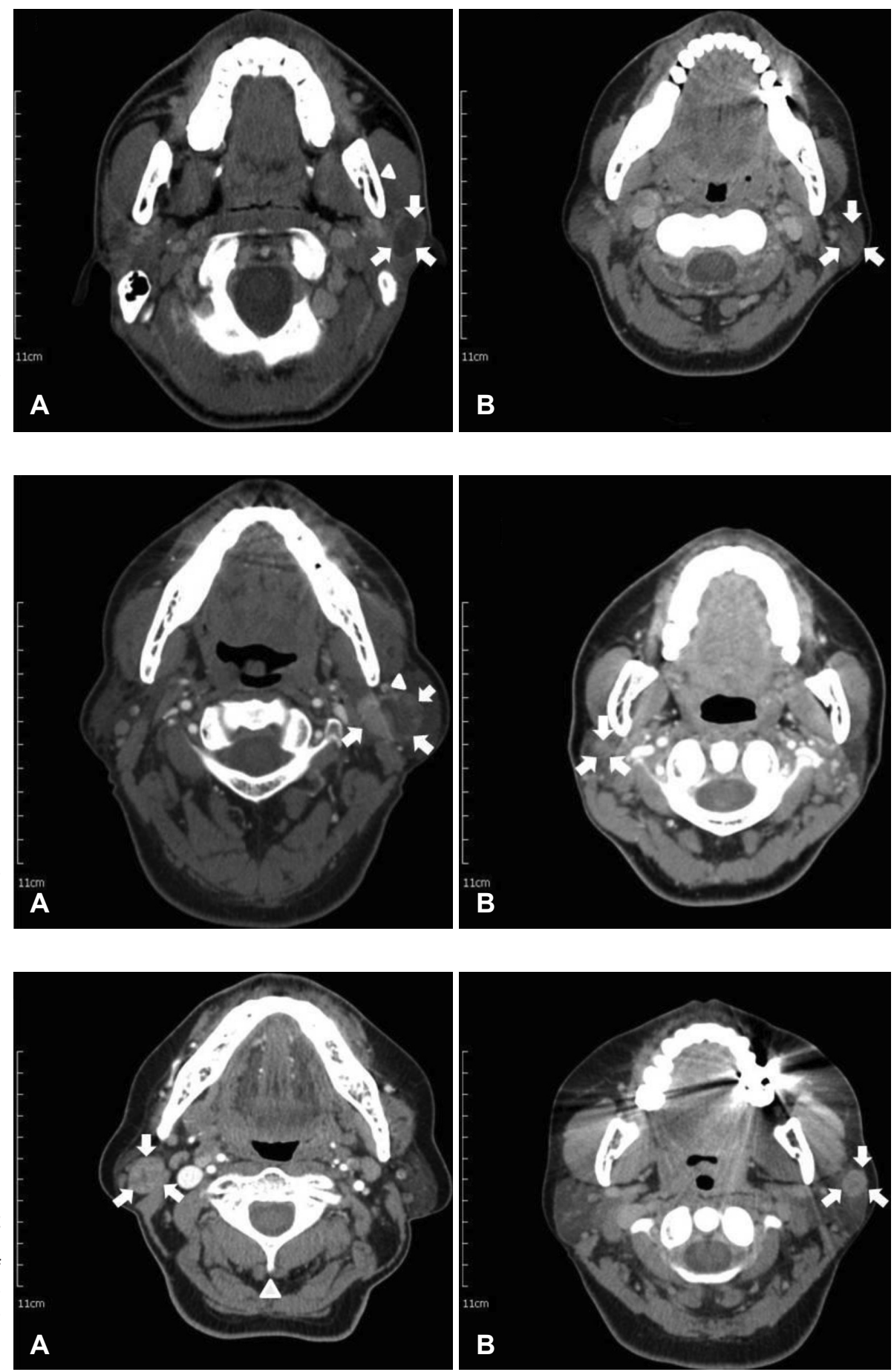
예측도(71.4\%) 모두 5가지 기준 중에서 가장 높게 나타났다 (Table 2). 하지만 FN line의 경우 다른 해부학적 지표에 비해 '교차종양'에 포함된 표본의 수가 작았고, 종양이 아래쪽에 위치한 경우 전산화단층촬영 이미지에서 턱뼈가지가 관찰되 지 않아 '적용 불가'에 해당하는 경우가 많은 한계점이 있다 (Table 1).

종양의 절반 이상이 해부학적 지표 안쪽에 위치할 경우를 심엽으로 분류한 기존의 방법을 사용할 경우, U line 을 제외 한 4가지 해부학적 지표에서 절단값을 사용할 경우보다 정확 도의 감소가 나타남을 확인 할 수 있었다(Table 2 and 3). 또 한 다른 연구에서 기존의 방법을 사용할 경우 A line, FN line, $\mathrm{RV}, \mathrm{CA}$ 는 $80 \%$ 이상의 정확도가 나타났고, U line은 $74.8 \%$ 의 정확도를 나타냈으나, ${ }^{2}$ 본 연구의 경우 5 가지 해부학적 지표 모두 $70 \%$ 이하의 정확도가 나타났다(Table 3). 기존 연구는 ‘천엽종양', '심엽종양', '교차종양'이 모두 포함 되었지만, 본 연구는 '교차종양'에 한정하여 분석을 시행했기 때문에 정확 도가 감소한 것으로 보인다. 종양의 크기가 커질 경우 심엽으 로 자라날수 있는 공간은 제한되어 있어 해부학적 지표보다 바깥쪽에 위치한 부분의 비율이 커질 수 있다. 이런 경우 기존 의 연구처럼 해부학적 지표 안쪽에 위치한 부분에 대한 비율 로 종양을 평가하게 된다면 심엽에 위치한 부분을 간과하게 될 수 있어 정확도가 낮게 나타난 것으로 보인다. 본 연구에 서 종양의 크기에 따른 예측 정확도에 대한 평가는 이루어 지 지 않아 추후 이에 대한 추가적 연구가 필요할 것으로 보인다. 해부학적 지표에 걸쳐있는 종양의 경우 객관적인 수치로 위치를 판단하는 연구는 현재까지 시행되지 않았다. 그래서 본 연구는 종양이 해부학적 지표에 걸쳐 있을 때 종양의 위치 를 파악하는데 도움을 주는 절단값을 최초로 구하였다.

본 연구는 전산화단층촬영만 이용하여 종양의 위치를 평가 했다는 한계가 있다. MRI의 경우 방사선 노출을 줄일 수 있 고 연부조직의 경계를 좀더 명확하게 볼 수 있는 장점이 있으 나 이하선 종양을 진단하는데 통계적으로 유의한 도움이 있 다고 밝혀지지는 않았다. ${ }^{9}$ 악성종양과 양성종양을 따로 분류
하지 않고 연구를 진행했지만, 이것이 결과에 영향을 주었을 가능성은 낮다고 생각된다. 안면신경의 해부학적 지표는 종 양의 위치, 크기에 따라 적용 가능성이 제한될 수 있으며 이 는 본 연구에서 제시한 방법이 일반적으로 적용될 수 없는 한 계점이기도 하다.

결론적으로 이하선 종양이 전산화단층촬영에서 안면신경 의 해부학적 지표와 교차하는 경우, 해당 해부학적 지표의 안 쪽에 위치하는 종양의 침범 정도를 $\mathrm{ROC}$ 커브 분석을 통해 구한 절단값을 기준으로 그 위치를 판단한다면 이하선 종양 의 위치를 보다 정확히 예측할 수 있다.

\section{REFERENCES}

1) Smith JR, King WW, Tang WY, Metreweli C. Differentiating tumours of the deep and superficial lobes of the parotid gland by computed tomographic sialography. Clin Radiol 1987;38(4):345-9.

2) Kim JY, Yang HC, Lee S, Kim HC, Shin DJ, Cho YB, et al. Effectiveness of anatomic criteria for predicting parotid tumour location. Clin Otolaryngol 2016;41(2):154-9.

3) Ariyoshi Y, Shimahara M. Determining whether a parotid tumor is in the superficial or deep lobe using magnetic resonance imaging. J Oral Maxillofac Surg 1998;56(1):23-6; discussion 26-7.

4) Kurabayashi T, Ida M, Ohbayashi N, Ishii J, Sasaki T. Criteria for differentiating superficial from deep lobe tumours of the parotid gland by computed tomography. Dentomaxillofac Radiol 1993;22 (2):81-5.

5) Divi V, Fatt MA, Teknos TN, Mukherji SK. Use of cross-sectional imaging in predicting surgical location of parotid neoplasms. $\mathrm{J}$ Comput Assist Tomogr 2005;29(3):315-9.

6) de Ru JA, Bleys RL, van Benthem PP, Hordijk GJ. Preoperative determination of the location of parotid gland tumors by analysis of the position of the facial nerve. J Oral Maxillofac Surg 2001;59 (5):525-8; discussion 529-30.

7) Conn IG, Wiesenfeld D, Ferguson MM. The anatomy of the facial nerve in relation to $\mathrm{CT} /$ sialography of the parotid gland. Br J Radiol 1983;56(672):901-5.

8) Ragbir M, Dunaway DJ, Chippindale AJ, Latimer J, Mohammed F, McLean NR. Prediction of the position of the intraparotid portion of the facial nerve on MRI and CT. Br J Plast Surg 2002;55(5):376-9.

9) Liu Y, Li J, Tan YR, Xiong P, Zhong LP. Accuracy of diagnosis of salivary gland tumors with the use of ultrasonography, computed tomography, and magnetic resonance imaging: A meta-analysis. Oral Surg Oral Med Oral Pathol Oral Radiol 2015;119(2):238-45.e2. 